原 著

\title{
破裂脳動脈瘤重症例の病態と治療
}

\author{
小野 純一, 山上岩男, 丹野 裕和, 興村 義孝 \\ 烏谷 博 英, 須田 純夫, 礒 部 勝見
}

\section{Clinical Features and Management in Severe Cases of Ruptured Intracranial Aneurysms}

Junichi Ono, M.D., Iwao Yamakami, M.D., Hirokazu TAnno, M.D., Yoshitaka OKImURA, M.D., Hirohide Karasudani, M.D., Sumio Suda, M.D., and Katsumi Isobe, M.D.

Department of Neurosurgery, Kimitsu Central Hospital, Kisarazu, Japan

Summary : In a consecutive series of 163 patients, who were operated on for ruptured anterior circulation aneurysm within three days after a subarachnoid hemorrhage, 93 patients (57\%) were classified as Hunt and Kosnik Grade III and IV (defined as severe cases), and 70 as Grade I and II (mild cases). Mean age, site of ruptured aneurysm and serial changes in mean blood pressure showed no significant difference between the two groups.

Postoperative electrolytes balance was examined on the 7th day after surgery. Both hyponatremia and hypernatremia were significantly frequent $(p<0.025, p<0.001$, respectively) in severe cases.

Septicemia, with or without disseminated intravascular coagulopathy, was the main postoperative complication in both groups. Over all, $26 \%$ of severe cases had systemic complications, whereas only $13 \%$ of mild cases had. This difference was statistically significant $(p<0.05)$. The outcome was considerably unfavorable in the patients with systemic complications.

Delayed ischemic neurological deterioration with irreversible deficits occurred in $30 \%$ of severe cases, but in only nine percent of mild cases $(p<0.005)$.

In CT findings, the amount of subarachnoid clot was classified into four groups, described by Fisher, et al. Group 3 (clot or thick layer), which was considered to be most responsible for symptomatic vasospasm, was frequently visualized with significant difference in severe cases $(p<0.05$; preoperatively, $p<0.005$; postoperatively). Hydrocephalus with shunt dependency occurred in $44 \%$ of severe cases but in only $13 \%$ of mild cases $(p<0.005)$.

In the serial measurement of mean hemispheric blood flow, reduced flow was continuously revealed in severe cases, as compared with mild cases. The difference was statistically significant on both the 14th day after surgery, and in the long-term follow-up $(p<0.05)$.

The ultimate outcome at six months was quite poor in severe cases. Only $56 \%$ had good outcome (good recovery and moderate disability) and $24 \%$ died, whereas $90 \%$ had good outcome and nine percent died in mild cases. These results suggest that postoperative systemic complications are of some prognostic value in predicting outcome, and it is stressed that systemic intensive care is also indispensable in the management of ruptured intracranial aneurysms.
Key words :

- ruptured aneurysm

- severe cases

- symptomatic vasospasm

- systemic complication

- cerebral blood flow 


\section{はじめに}

脳動脈瘤破裂によるクモ膜下出血の病態はいまだ不明な 点が多く, 治療に窮することもまれではない. また, 神経 学的所見, CT 所見, 脳循環動態などの頭蓋内因子と転帰 との関係は数多く報告されているが, 全身状態との相関に 関してあまり注目されていない. 今回は重症例を Hunt \& $\operatorname{Kosnik}^{1)}$ grade III, IVの症例と定義し, その病態および転 鹵を分析する目的で, 神経症状, 全身状態, CT 所見, 脳 循環動態の経時的変化などに注目し, 軽症例と比較検討し たので，若干の文献的考察を加えて報告する.

\section{対象および方法}

対象は発症後72時間以内に当科に搬入され，急性期に根 治術が施行されたWillis 輪前半部の破裂脳動脈瘤例163例 (Table 1)である. 内訳は Hunt \& Kosnik grade I, IIの 軽症例70例と grade III, IV の重症例93例である. 平均年齢 は重症例で55歳と, 軽症例の53歳と比較して有意差はなく, また動脈瘤の部位, 多発性に関しても両者間に有意差を認 めなかった. なお, grade Vは急性期手術の適応外と考え ているため今回の分析から除外した．治療方針はすべての

Table 1 Summary of 163 cases with ruptured aneurysm of anterior circulation

\begin{tabular}{lcc}
\hline & Mild cases & Severe cases \\
\hline Hunt \& Kosnik grade & I , II & III, IV \\
No. of cases (cases) & 70 & 93 \\
Mean age (years) & $53.6 \pm 11.3$ & $55.0 \pm 11.4$ \\
Site of aneurysm: & & \\
$\quad$ internal carotid & $36 \%$ & $25 \%$ \\
$\quad$ anterior cerebral & $36 \%$ & $39 \%$ \\
$\quad$ middle cerebral & $27 \%$ & $35 \%$ \\
multiplicity & $17 \%$ & $15 \%$ \\
\hline
\end{tabular}

Table 2 Postoperative electrolytes imbalance Mild cases

\begin{tabular}{|c|c|c|c|c|}
\hline \multirow{2}{*}{ Electrolytes } & \multirow{2}{*}{$\begin{array}{c}\text { No. of } \\
\text { cases }\end{array}$} & \multicolumn{3}{|c|}{ Outcome } \\
\cline { 3 - 5 } & GR/MD & SD/PVS & Dead \\
\hline Hyponatremia & $\begin{array}{c}11^{+} \\
(16 \%)\end{array}$ & 9 & 0 & 2 \\
$(82 \%)$ & & $(18 \%)$ \\
Hypernatremia & $2^{+}$ & 0 & 0 & 2 \\
$(3 \%)$ & & & $(100 \%)$ \\
\hline Total & $\begin{array}{c}13 \\
(19 \%)\end{array}$ & 9 & 0 & $\begin{array}{c}4^{*} \\
(70 \%)\end{array}$ \\
\hline Normonatremia & 57 & 54 & 1 & $2^{*}$ \\
$(81 \%)$ & $(94 \%)$ & $(2 \%)$ & $(6 \%)$ \\
\hline \multicolumn{5}{|c|}{$* P<0.005+P<0.025$}
\end{tabular}

症例で，急性期に根治術およびクモ膜下血腫の可及的除去 を施行し，脳槽ドレナージは原則として設置していない. 術後は plasma 製剤による hypervolemic therapyを施行し, ヘマトクリット值を $35 \%$ 前後に調節し，また症例によって は dopamine による induced hypertensionも併用した. カ ルシュウム拮抗剤, バルビツュレートなどの特殊な薬剤は 投与していない.

分析項目としては, 術前後の血圧変化, 術後の血清ナト リウム值の異常, 全身合併症の有無, 遅発性虚血性神経脱 落症状の有無, 術後の脳血流量の経時的変化について分析 した。脳血流量 ${ }^{2)}$ は133 Xe 吸入法を用い, initial slope index 算出して, 平均半球血流量として表わし, 開頭側の 值を比較検討した。 なお, 当院における平均半球血流量の 正常值は $65 \pm 10 \mathrm{ml} / 100 \mathrm{gm} / \mathrm{min}$ (平均年齢：50土9 歳)で ある。またCT 所見では, Fisher $5^{3)}$ の分類によるクモ膜 下血腫量の経時的変化，水頭症の有無につき分析した．転 帰は Glasgow outcome scale covery と moderate disability を合わせて転帰良好群と定 義した. なお, 統計学的分析には $\chi^{2}$ 検定, $t$ 検定を用い, $5 \%$ 未満を有意とした。

\section{結 果}

\section{1. 術前後の血圧変化および術後の血清ナトリウム値の異 常 (Table 2)}

術前後の平均血圧の変化について検討したが, 重症例と 軽症例の間に統計学的有意差を認めなかった. 次に, 術後 7 日目における血清ナトリウム值を比較検討した．重症例 における低ナトリウム血症, 高ナトリウム血症の発現率は それぞれ $34 \% ， 20 \%$ と軽症例の $16 \% ， 3 \%$ に比して有意に 高く，またナトリウム值の異常を呈した例全体の転帰は 重・軽症例ともにナトリウム值正常例と比較して, 有意に 不良であった。

\begin{tabular}{|c|c|c|c|c|}
\hline \multirow{2}{*}{ Electrolytes } & \multirow{2}{*}{$\begin{array}{l}\text { No. of } \\
\text { cases }\end{array}$} & \multicolumn{3}{|c|}{ Outcome } \\
\hline & & GR/MD & SD/PVS & Dead \\
\hline Hyponatremia & $\begin{array}{r}32^{+} \\
(34 \%)\end{array}$ & $\begin{array}{c}15 \\
(47 \%)\end{array}$ & $\begin{array}{c}9 \\
(28 \%)\end{array}$ & $\begin{array}{c}8 \\
(25 \%)\end{array}$ \\
\hline Hypernat remia & $\begin{array}{c}19^{+} \\
(20 \%)\end{array}$ & $\begin{array}{c}4 \\
(21 \%)\end{array}$ & $\begin{array}{c}5 \\
(27 \%)\end{array}$ & $\begin{array}{c}10 \\
(53 \%)\end{array}$ \\
\hline Total & $\begin{array}{c}51 \\
(55 \%)\end{array}$ & $\begin{array}{c}19 \\
(38 \%)\end{array}$ & $\begin{array}{c}14 \\
(28 \%)\end{array}$ & $\begin{array}{r}18^{5} \\
(35 \%)\end{array}$ \\
\hline Normonatremia & $\begin{array}{c}42 \\
(45 \%)\end{array}$ & $\begin{array}{c}33 \\
(78 \%)\end{array}$ & $\begin{array}{c}5 \\
(12 \%)\end{array}$ & $\begin{array}{r}4^{8} \\
(10 \%)\end{array}$ \\
\hline
\end{tabular}

cf. GR : good recovery, $M D$ : moderate disability, $S D$ : severe disability PVS: persistent vegetative state 
Table 3 Postoperative systemic complications and outcome

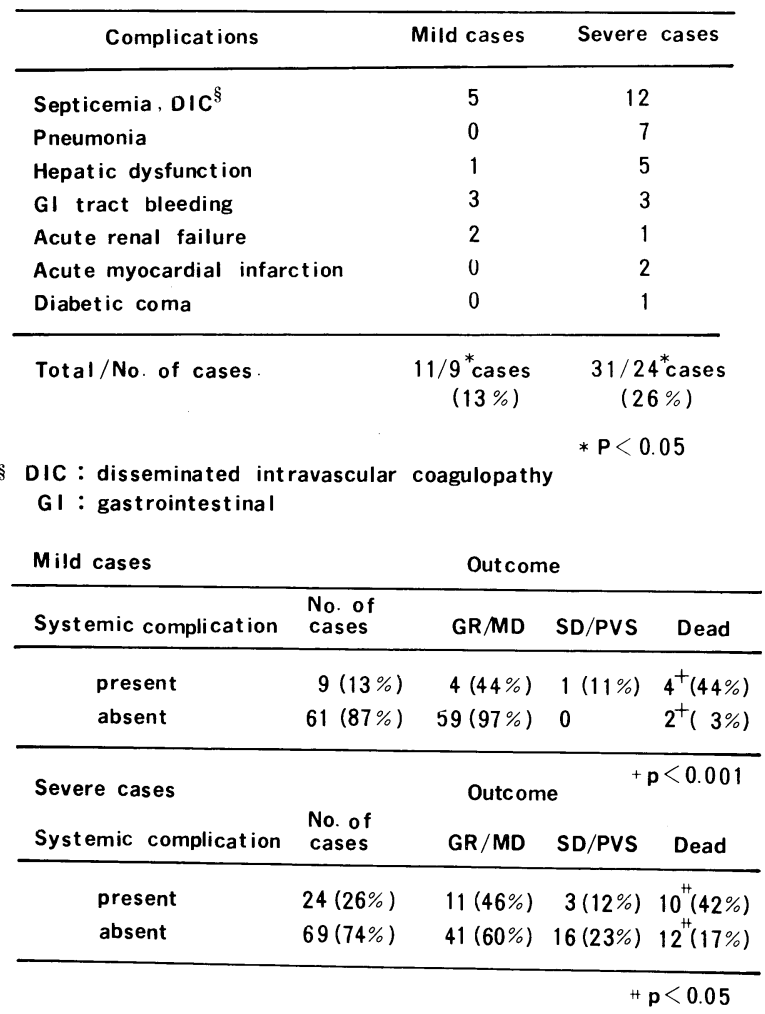

\section{2. 術後の全身合併症 (Table 3)}

全身合併症の内訳は重・軽症例ともに敗血症が最も多く, さらに重症例では肺炎, 肝機能障害, 消化管出血が, 軽症 例では消化管出血，急性腎不全などが高頻度に認められた。 全身合併症の出現頻度は重症例で 24 例 $(26 \%) / 31$ 件と，軽 症例の 9 例 $(13 \%) / 11$ 件に比し有意に高率であった。また 全身合併症を有した例の転帰は重・軽症例ともに有意に不

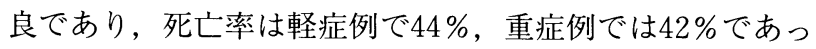
た。一方，有しなかった例の転帚は軽症例ではきわめて良 好であり，重症例でも死亡率はわずかに17\%であった。

\section{3，遅発性虚血性神経脱落症状 (Table 4)}

遅発性虚血性神経脱落症状が可逆的であった群と不可逆 的であった群に分類し検討した。可逆的であった群は軽症 例の $11 \%$, 重症例の $14 \%$ を占め, その出現頻度に差を認め ず，転帰も有意差を認めなかった。一方，不可逆的であっ た群は軽症例では $9 \%$ を占めるにすぎないが, 重症例では 30\%をも占め, この差は有意であった. しかし，この群の 転帰も両者間に有意差を認めなかった。 逆に, 遅発性虚血 性神経脱落症状が出現しなかった群は重症例で有意に少な い.
Table 4 Delayed ischemic neurological deterioration

Reversible DIND

\begin{tabular}{|c|c|c|c|c|c|c|}
\hline \multirow{2}{*}{ Grade } & \multirow{2}{*}{$\begin{array}{c}\text { No. of } \\
\text { cases }\end{array}$} & \multicolumn{5}{|c|}{ Outcome } \\
\hline & & $G R$ & $M D$ & SD & PVS & Dead \\
\hline Mild & $\begin{array}{c}8 / 70 \\
(11 \%)\end{array}$ & $\begin{array}{c}8 \\
(100 \%)\end{array}$ & 0 & 0 & 0 & 0 \\
\hline Severe & $\begin{array}{c}13 / 93 \\
(14 \%)\end{array}$ & $\begin{array}{c}11 \\
(85 \%)\end{array}$ & $\begin{array}{c}2 \\
(15 \%)\end{array}$ & 0 & 0 & 0 \\
\hline
\end{tabular}

Irreversible DIND

\begin{tabular}{|l|c|c|c|c|c|c|}
\hline \multirow{2}{*}{ Grade } & \multirow{2}{*}{$\begin{array}{l}\text { No. of } \\
\text { cases }\end{array}$} & \multicolumn{6}{|c|}{ Outcome } \\
\cline { 3 - 7 } & GR & MD & SD & PVS & Dead \\
\hline Mild & $\begin{array}{c}6^{*} / 70 \\
(9 \%)\end{array}$ & 0 & $\begin{array}{c}2 \\
(33)\end{array}$ & $\begin{array}{c}1 \\
(17 \%)\end{array}$ & 0 & $\begin{array}{c}3 \\
(50 \%)\end{array}$ \\
\hline Severe & $\begin{array}{c}28^{*} / 93 \\
(30 \%)\end{array}$ & 0 & $\begin{array}{c}9 \\
(30)\end{array}$ & $\begin{array}{c}5 \\
(18 \%)\end{array}$ & $\begin{array}{c}4 \\
(14 \%)\end{array}$ & $\begin{array}{c}10 \\
(36 \%)\end{array}$ \\
\hline
\end{tabular}

No. DIND

\begin{tabular}{|c|c|c|c|c|c|c|}
\hline \multirow{2}{*}{ Grade } & \multirow{2}{*}{$\begin{array}{l}\text { No. of } \\
\text { cases }\end{array}$} & \multicolumn{5}{|c|}{ Outcome } \\
\hline & & GR & MD & SD & PVS & Dead \\
\hline Mild & $\begin{array}{l}56 / 70 \\
(80 \%) \\
\end{array}$ & \begin{tabular}{|c|}
51 \\
$(91 \%)$ \\
\end{tabular} & $\begin{array}{c}2 \\
(4 \%) \\
\end{array}$ & 0 & 0 & $\begin{array}{c}3^{+} \\
(5 \%) \\
\end{array}$ \\
\hline Severe & $\begin{array}{l}52 / 93 \\
(56 \%) \\
\end{array}$ & $\begin{array}{c}23 \\
(44 \%) \\
\end{array}$ & $\begin{array}{c}7 \\
(13 \%) \\
\end{array}$ & $\begin{array}{c}7 \\
(13 \%) \\
\end{array}$ & $\begin{array}{c}3 \\
(6 \%) \\
\end{array}$ & $\begin{array}{c}12^{+} \\
(23 \%) \\
\end{array}$ \\
\hline & & 005 & & & & $<0.01$ \\
\hline
\end{tabular}

\section{CT 所見}

\section{(1)クモ膜下血腫量の経時的変化 (Fig. 1)}

Fisher らの分類に従い, CT 上のクモ膜下血腫量を経時 的に検討すると, 重症例では脳血管攣縮の発現に関係する といわれている, Group 3, すなわち clot or thick layer が 術前で $60 \%$ ，さらに術後 7 日目においても $45 \%$ に認められ， 軽症例のそれぞれ $43 \% ， 6 \%$ に比し有意に高率に認められ る所見であった。

\section{(2)水頭症 (Fig. 2)}

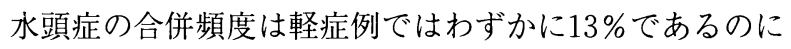
対し，重症例では44\%にも認められ，この差は有意であっ た. 重症例をさらにHunt \& Kosnik grade III とIVの 2 群に 分類すると, 水頭症の合併率は grade IIIで $40 \%$, grade IV で54\%と後者でやや高率であったが, 統計学的有意差は認 められなかった。

\section{5. 術後の脳血流量の経時的変化 (Fig. 3)}

脳血流量は術後 1 3 日の早期，7 日，14日，21日目と 6 か月以上の長期に測定したが, 脳内血腫, 脳室内血腫お よび水頭症合併例は対象から除外した。重症例における平 均半球血流量は軽症例と比較して, 術後早期より低值を示 し，とくに術後14日目で両者の差は有意であった。長期 follow-up においても軽症例では脳血流量はほぼ正常值に 


\section{Mild}

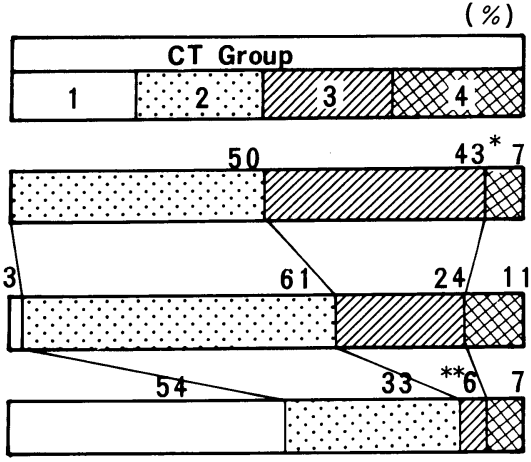

\section{Severe}

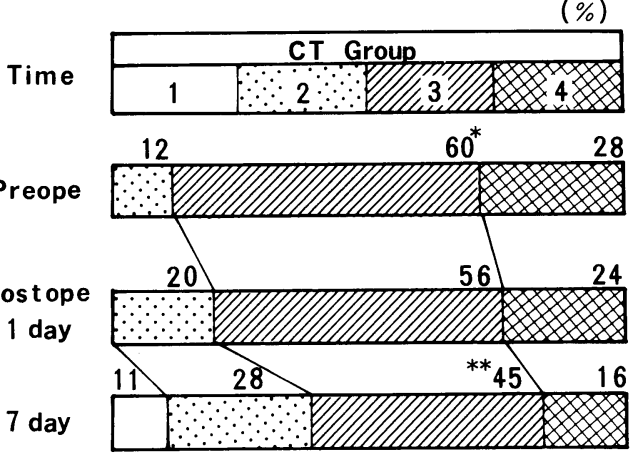

* $\mathrm{P}<0.05, \quad * * \mathrm{P}<0.005$

Fig. 1 Dyamic change in CT group of subarachnoid hemorrhage (classified by Fisher, et al)

復するのに対し，重症例では依然低值を示し，この差も有 意であった．重症例をさらに Hunt \& Kosnik grade III と IVに分類すると, grade IVにおける平均半球血流量は grade IIIに比し，術後 7 日目より長期 follow-up に至るま で有意に低值が持続した。

\section{6．転帰および死亡原因（Table 5)}

発症 6 か月後の転帰を比較検討した，重症例における転 帰は良好群が $56 \%$ ，死亡群が $24 \%$ と，軽症例のそれぞれ $90 \% ， 9 \%$ と比較して有意に不良であった．さらに重症例 を Hunt \& Kosnik grade III とIVに細分してみると，死亡 率は両者間に有意差を認めないが，転帰良好群は grade III

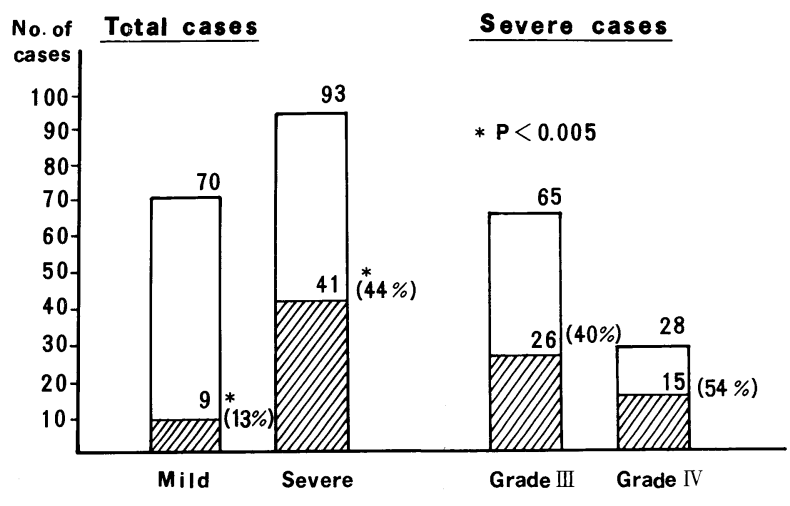

Fig. 2 Incidence of hydrocephalus
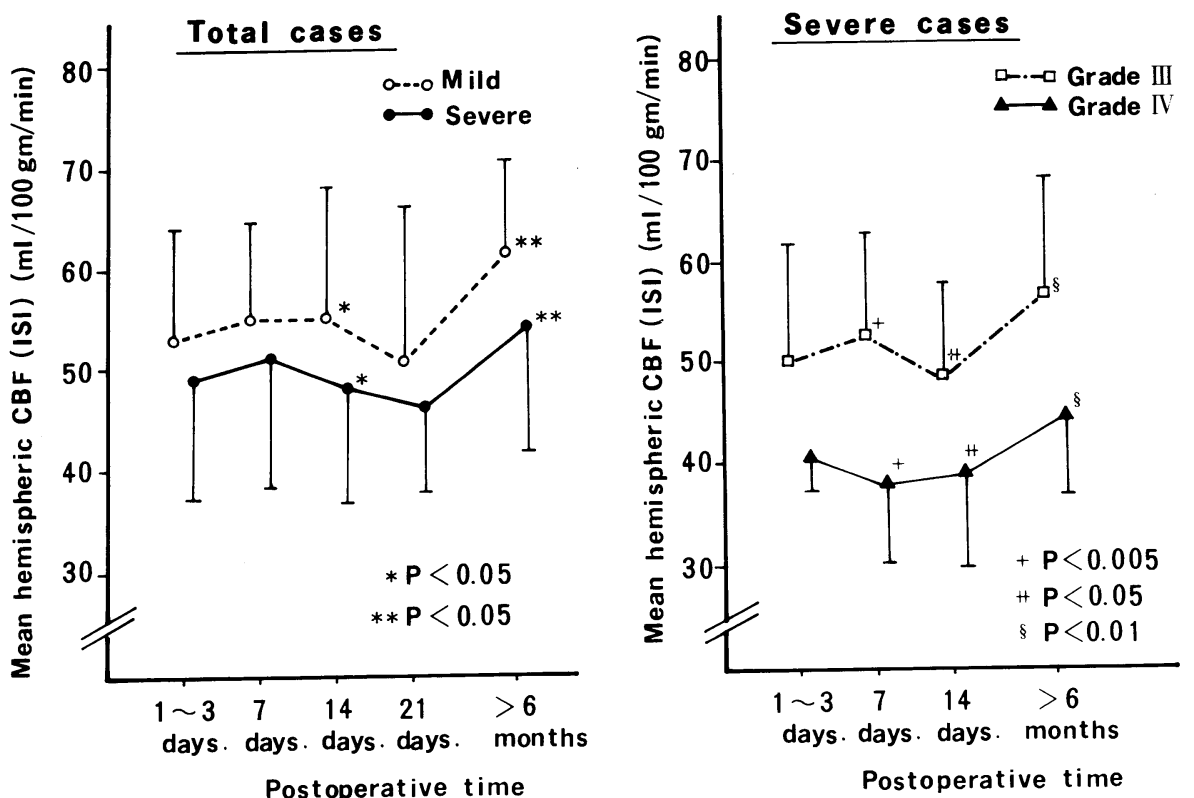

Fig. 3 Dynamic change in hemispheric cerebral blood flow 
では $69 \%$ であるのに対し, grade IVではわずかに $25 \%$ と有 意に低率であった $(p<0.005)$.また，死亡原因の分析に おいて, 頭蓋外合併症の占める割合は軽症例では全死亡例 の $67 \%$, 重症例では45\%であり, 両者ともに敗血症性ショ ック，消化管出血などの低血圧を引き起こす病態が中心で あった。

\section{考察}

破裂脳動脈瘤急性期手術例の検討で，転带に影響を及ぼ す頭蓋内因子の分析は数多く報告されており，とくにCT の重要性については Auer $ら^{5)}$, Gurusinghe $ら^{6)}$, Davis $ら^{7)}$ などが言及し，独自の分類， scoring をもとに脳血管 攣縮の発現，転帰との関係について検討している，今回の 検討では Fisher ら ${ }^{3)}$ の分類を用い経時的に分析した結果, 重症例では軽症例と比較して, 発症直後のクモ膜下血腫量 が多く，それが手術操作によっても除去されにくく，症候 性脳血管攣縮や水頭症の発現 ${ }^{8)}$ に相関するものと考えられ た. 他の因子として, Kassell $ら^{9)}$, Ljunggren ら ${ }^{10)}$ は morbidity, mortalityの主因として，症候性脳血管攣縮を 強調しており, 今回の分析でも重症例は症候性脳血管攣縮, とくにそれが不可逆的となる例が有意に高率に認められ， 諸家の報告と一致した結果が得られた。

また，破裂脳動脈瘤例における脳循環動態と Hunt \& Kosnik neurological grade ${ }^{1)}$ との関係では，重症度が高い ほど，発症直後より脳血流量は低值を示し，とくに grade III と IV との差が大きいことはすでにVoldby ら ${ }^{11)}$, Ishii ${ }^{12)}$ によって報告されている. 今回の分析でも同一の結果が得 られたが，これは山形ら ${ }^{13)}$ が総括しているように，クモ 膜下出血自体による ischemic insult と考えられた。ささ に脳血流量の経時的変化の検討でも，重症例では術後21日 目に至るまで低脳血流状態が持続し, Yasui $~^{14)}$ の報告と 一致するが，このことは脳血管攣縮やその他の原因による 頭蓋内圧六進などによる結果と考えられ，転帰を左右する 因子として，治療上重要な所見と考えられた。

他方，全身的因子に関する報告はきわめて少なく， Kassell ら ${ }^{9)}$ は cooperative aneurysm study の中で medical complications が disability と deathの原因として1.6\%を 占めるとし，また，篠原ら ${ }^{15)}$ は破裂脳動脈瘤を全身疾患 として把握すべきであり, 水電解質異常や消化管出血が脳 血管攣縮の治療上の阻害因子となることを報告しているに すぎない. 今回の分析からは, 電解質の異常や敗血症性シ ヨック, 消化管出血などの低血圧を引き起こす全身合併症 が高率に併発することが証明された.

以上の分析より, 破裂脳動脈瘤重症例では種々の頭蓋内 因子により頭蓋内圧方進, 脳血流量の低下が長期にわたっ て持続する上に，全身的因子が相加することにより，vi-
Table 5 Outcome at 6 months after onset of subarachnoid hemorrhage

\begin{tabular}{|c|c|c|c|c|c|c|}
\hline \multirow{2}{*}{ Grade } & \multirow{2}{*}{$\begin{array}{c}\text { No. of } \\
\text { cases }\end{array}$} & \multicolumn{6}{|c|}{ Outcome } \\
\cline { 3 - 7 } Mild & 70 & $\begin{array}{c}59 \\
(84 \%)\end{array}$ & $\begin{array}{c}4 \\
(6 \%)\end{array}$ & $\begin{array}{c}1 \\
(1 \%)\end{array}$ & 0 & $\begin{array}{c}6^{*} \\
(9 \%)\end{array}$ \\
\hline Severe & 93 & $\begin{array}{c}34 \\
(37 \%)\end{array}$ & $\begin{array}{c}18 \\
(19 \%)\end{array}$ & $\begin{array}{c}12 \\
(13 \%)\end{array}$ & $\begin{array}{c}7 \\
(8 \%)\end{array}$ & $\begin{array}{c}22 * \\
(24 \%)\end{array}$ \\
III & 65 & $\begin{array}{c}30 \\
(46 \%)\end{array}$ & $\begin{array}{c}15 \\
(23 \%)\end{array}$ & $\begin{array}{c}5 \\
(8 \%)\end{array}$ & $\begin{array}{c}2 \\
(3 \%)\end{array}$ & $\begin{array}{c}13 \\
(20 \%)\end{array}$ \\
II & 28 & $\begin{array}{c}4 \\
3\end{array}$ & $\begin{array}{c}7 \\
(14 \%)\end{array}$ & $\begin{array}{c}3 \\
(11 \%)\end{array}$ \\
$(25 \%)$ & $(18 \%)$ & $(32 \%)$ \\
\hline Tot a I & 163 & $\begin{array}{c}93 \\
(57 \%)\end{array}$ & $\begin{array}{c}22 \\
(13 \%)\end{array}$ & $\begin{array}{c}13 \\
(8 \%)\end{array}$ & $\begin{array}{c}7 \\
(4 \%)\end{array}$ & $\begin{array}{c}28 \\
(17 \%)\end{array}$ \\
\hline
\end{tabular}

Cause of death

\begin{tabular}{|c|c|c|c|c|}
\hline \multirow[b]{2}{*}{ Grade } & \multirow{2}{*}{$\begin{array}{l}\text { No. of } \\
\text { dead } \\
\text { cases }\end{array}$} & \multicolumn{3}{|c|}{ Medical death } \\
\hline & & $\begin{array}{l}\text { No. of } \\
\text { cases }\end{array}$ & Cause of death & \\
\hline Mild & 6 & $\begin{array}{c}4 \\
(67 \%)\end{array}$ & $\begin{array}{l}\text { Septic shock } \\
\text { Gastrointestinal bleeding }\end{array}$ & $\begin{array}{l}3 \\
1\end{array}$ \\
\hline Severe & 22 & $\begin{array}{c}10 \\
(45 \%)\end{array}$ & $\begin{array}{l}\text { Septic shock } \\
\text { Gastrointestinal bleeding } \\
\text { Acute myocardial infarction } \\
\text { Acute heart failure }\end{array}$ & $\begin{array}{l}6 \\
1 \\
2 \\
1\end{array}$ \\
\hline
\end{tabular}

cious cycle を形成して転帰を一層覀化させていることが 示唆され, 治療上全身管理の重要性が強調された。

\section{文献}

1) Hunt WE, Kosnik EJ: Timing and perioperative care in in tracranial aneurysm surgery. Clin Neurosurg 21: 79-89, 1974

2) Yamakami I, Isobe $\mathrm{K}$, Yamaura A, et al: Vasospasm and regional cerebral blood flow in patients with ruptured in tracranial aneurysm: Serial rCBF studies with xenon-133 in. halation method. Neurosurgery 13: 394-401, 1983

3) Fisher CM, Kistler JP, Davis JM: Relation of cerebral vasospasm to subarachnoid hemorrhage visualized by computerized tomographic scanning. Neurosurgery 6: 1-9, 1980

4) Jennett B, Bond $M$ : Assessment of outcome after severe brain damage. A practical scale. Lancet 1: 480-484, 1975

5) Auer LM, Schneider GH, Auer T: Computerized tomography and prognosis in early aneurysm surgery. J Neurosurg 65: $217-221,1986$

6) Gurusinghe NT, Richardson AE: The value of computerized tomography in aneurysmal subarachnoid hemorrhage. The concept of the CT score. J Neurosurg 60: 763-770, 1984

7) Davis JM, Davis KR, Crowell RM: Subarachnoid hemorrhage secondary to ruptured intracranial aneurysm: Prognostic significance of cranial CT. AJR 134: 711-715, 1980

8）井澤一郎，頃末和良，浜野聖二，ほか：脳動脈瘤破裂によ 
るクモ膜下出血後の水頭症と脳血管攣縮. 脳神経外科 $\mathbf{1 6}$ 487-492, 1988

9) Kassell NF, Torner JC: The international cooperative study on timing of aneurysm surgery - An update. Stroke 15: $566-570,1984$

10) Ljunggren B, Säveland $\mathrm{H}$, Brandt L, et al: Causes of unfavorable outcome after early aneurysm operation. Neurosurgery 13: 629-633, 1983

11) Voldby B, Enevoldsen EM: Jensen FT: Regional CBF, intraventricular pressure, and cerebral metabolism in patients with ruptured intracranial aneurysms. J Neurosurg 62: $48-58,1985$
12) Ishii R: Regional cerebral blood flow in patients with ruptured intracranial aneurysms. J Neurosurg 50: 587-594, 1979

13）山形 専, 菊池晴彦, 伊原郁夫, ほか : クモ膜下出血後の 脳循環動態. 転帰不良例における検討. 脳神経外科 $\mathbf{1 5}$ 1189-1196, 1987

14) Yasui $N$, Ito $Z$, Ohta $H$, et al: Surgical problems and pathophysiology in severe cases with ruptured aneurysm in the acute stage. Acta Neurochir (Wien) 63: 163-174, 1982

15）篠原義賢，渡辺義郎，佐藤 章，ほか：全身疾患としての 破裂脳動脈瘤. 第46回日本脳神経外科学会総会抄録集, 1987 